\title{
Reviewers' Comments in Academic Journal Peer Review Reports: A Speech Act Theory Perspective
}

\author{
Wee Chun $\operatorname{Tan}^{1}$ \\ ${ }^{1}$ Universiti Putra Malaysia, Selangor, Malaysia \\ Correspondence: Wee Chun Tan, Universiti Putra Malaysia, UPM Serdang, Selangor, Malaysia. E-mail: \\ weechun@upm.edu.my
}

Received: September 2, 2021

Accepted: October 12, $2021 \quad$ Online Published: October 22, 2021

doi:10.5539/ijel.v11n6p40

URL: https://doi.org/10.5539/ijel.v11n6p40

\begin{abstract}
This study sought to investigate the linguistic functions of reviewers' comments in academic journal peer review reports, primarily from a pragmatics perspective. Drawing on Searle's (1976) Speech Act Theory (SAT), reviewers' comments from 20 academic journal peer review reports were qualitatively analysed. The analysis revealed two main types of speech acts, directive and expressive speech acts, underlined the reviewers' comments. Among the two types of speech acts, the directive speech act was preferred by the majority of the reviewers. It was also found that the expressive speech act was much more prominent when the reviewers provided negative comments. The results obtained suggest the need for a collegial peer review with more positive and constructive suggestions by reviewers.
\end{abstract}

Keywords: speech act theory, reviewers' comments, academic journal peer review reports, pragmatics

\section{Introduction}

\subsection{Academic Journal Peer Review}

In the context of journal publications, peer review is a common scholarly activity. Submitted manuscripts are subjected to peer review before they can be accepted for publication in an academic journal. Authors must address the reviewers' comments satisfactorily (Fortanet, 2008). Oftentimes, peer review is viewed as indispensable for building academic credibility, and it is essential to the development of novel research and contributions to the existing academic literature (Hyland, 2015). It is "the most effective mechanism for ensuring the reliability, integrity, and consistency of the scholarly literature" (Mulligan et al., 2013, p. 149). There is no doubt that many universities these days consider peer-reviewed publications as a measure of academic excellence, and appointments and promotions are typically based on peer-reviewed work (Tardy, 2019).

In academic journal peer review, reviewers play an essential role as quality control agents. They contribute toward the development of research, which is likely to increase citation counts of published papers (Rigby et al., 2018). Reviewers review manuscripts, provide written comments, and recommend decisions to the journal editor on whether to accept the manuscript with or without revision. As they carry out the review, they write their comments in the accompanying journal peer review reports. After receiving the peer review reports, the authors will have to address the reviewers' comments to enable their manuscripts to be considered favourably for publication in the journal (Hames, 2007). There is also the possibility that reviewers could recommend the journal editor to reject the manuscript, of which, they are often willing to provide reviewers' comments for the purpose of improvement.

In this sense, academic journal peer review constitutes a form of communication. In providing comments on the manuscript, reviewers communicate with authors using the means of language. Language, as a communication tool, is used to convey the reviewers' comments (messages) and to inform the authors (receivers) of the reviewers' (senders') communicative intentions. The written comments are packed with information to help the authors improve and learn (Kourilová, 1998; Paltridge, 2017). To express what is on the reviewer's mind, reviewers often write sentences in peer review reports. These sentences produced by the reviewers are not only meant to inform or explain to the authors what the reviewers are thinking, but also as a means of asking authors to revise their manuscripts. Hence, reviewers' comments are essential in assisting authors in producing high-quality manuscripts (Gosden, 2003; Shashok, 2008). 


\subsection{Reviewers' Comments}

While addressing the reviewers' comments, authors need to understand what the reviewers convey. For example, if a reviewer's statement was along these lines: 'You are wasting my time reading this manuscript.' This sentence will require the author to understand the meaning of the sentence. The author can interpret the sentence as an expression of one's feelings or a request to revise the manuscript significantly to meet the standards of research and the journal. If the author does not know the intended meaning of the reviewer, this might challenge the author in carrying out the intended revision.

Moreover, academic journals usually employ a blind peer review process, where the identities of the authors and reviewers are anonymised. Hence, the authors may not be able to communicate with the reviewers for immediate clarification. This shows the importance of communication between the reviewers and authors, which must be made clear through reviewers' comments (Kourilová, 1996). It is, therefore, necessary to make sense of the comments made by reviewers in academic journal peer review reports.

\subsection{Statement of the Problem}

Despite the crucial role reviewers' comments may have in academic journal peer review reports for enhancing the quality of research and writing for journal publications, such reviewers' comments have received insufficient attention from linguistics researchers, especially in the field of pragmatics. This may be due to the fact that academic journal peer review reports are an occluded academic genre (Falkenberg \& Soranno, 2018; Swales, 1996). These reports are typically private and confidential, and they are not readily accessible to the public, except when authors publish their reviews on the internet. Only journal editors and corresponding authors can access these reports. As such, the difficulty of accessing private documents limits research on reviewers' comments.

In acknowledging academic journal peer review as a crucial form of communication, with reviewers' comments being the accompanying message, this study sought to contribute to the literature on pragmatics in two ways. Mey (2001) defined pragmatics as the circumstances under which the language is used for human communication. In order to communicate using language, human beings rely on the premises of society. Within this area of linguistics research, researchers study how speakers use language to fulfil their goals within their limitations and abilities. The study first investigates the linguistic functions to uncover the underlying characteristics of reviewers' comments in journal peer review reports from a speech act theory perspective. Additionally, this study demonstrates how reviewers use language to reflect on their intentions and suggest the next course of action.

\subsection{Purpose of the Study}

This study aims to examine the speech acts of reviewers' comments in academic journal peer review reports by answering the following research questions:

1) What types of speech acts are used by reviewers when providing written comments on manuscripts?

2) What are the most recurring types of speech acts used by reviewers when providing written comments on these manuscripts?

\section{Literature Review and Theoretical Background}

\subsection{Selected Studies on Reviewers' Comments in Academic Journal Peer Review Reports}

Several researchers have examined the language of reviewers' comments in academic journal peer review reports from across different aspects, including the functions of language, evaluative language, focus, requests and criticisms (Fortanet, 2008; Gosden, 2003; Hyland \& Jiang, 2020; Kourilová, 1996, 1998; Paltridge, 2015). Kourilová (1996) is perhaps the pioneer when it comes to looking at the communication between authors and reviewers in academic journal peer review. She revealed that many reviewers tend to criticise the authors due to the effect of anonymity. In a follow-up study, Kourilová (1998) pointed out that it is crucial to recognise the communicative purposes and genre conventions of reviews to understand the reviewer's intentions much better.

Gosden (2003) examined reviewers' comments on content (ideational), language (interpersonal), and format (textual). He found that reviewers' comments were focused much more on the language (interpersonal) part to improve the communication between authors and readers. Alternatively, Fortanet (2008) conducted a study to find the evaluative language used by the reviewers in academic journal peer review reports. She found that the reviewers' comments consisted of criticism (attribution), recommendation, and requests (direct and indirect).

To examine the requests in reviewers' comments, Paltridge (2015) surveyed 45 reviewers and analysed 95 review reports. He concluded that reviewers worded their requests for changes as directions, suggestions, 
clarification requests, and recommendations. The reviewers made indirect requests for changes much more than direct changes.

In a recent study, Hyland and Jiang (2020) examined 850 negative reviews posted on the shitmyreviewerssay website. They first examined the evaluative focus of reviewers. Then, they examined the stance reviewers took by analysing the linguistic markers of epistemic and attitudinal stance. They found that the reviewers' comments were provided across five areas; author competence, overall verdict, the quality of the arguments, structure and language, and research design.

These studies have shown a growing interest in reviewers' comments, and the findings of these studies will help shed light on the language used, and the reviewer's practices in academic journal peer review.

\subsection{Speech Act Theory (SAT)}

SAT provides the basis for studying linguistic functions of reviewers' comments in academic journal peer review reports. It describes how language can be used to do things instead of referring to the truth or false aspect of a particular statement (Austin, 1962; Searle, 1969). SAT originated from John Langshaw Austin's work, How to Do Things with Words, in 1962. Searle (1976, 1979), who had studied under Austin in the 1950s, further developed and codified SAT. SAT proposes the idea that words are utterances which indicate an action rather than just a statement. These utterances are referred to as performative sentences. These sentences do not just provide information, but they perform actions or speech acts. According to SAT (Austin, 1962), performative utterances consist of three linguistic acts: locutionary, illocutionary, and perlocutionary (Figure 1).

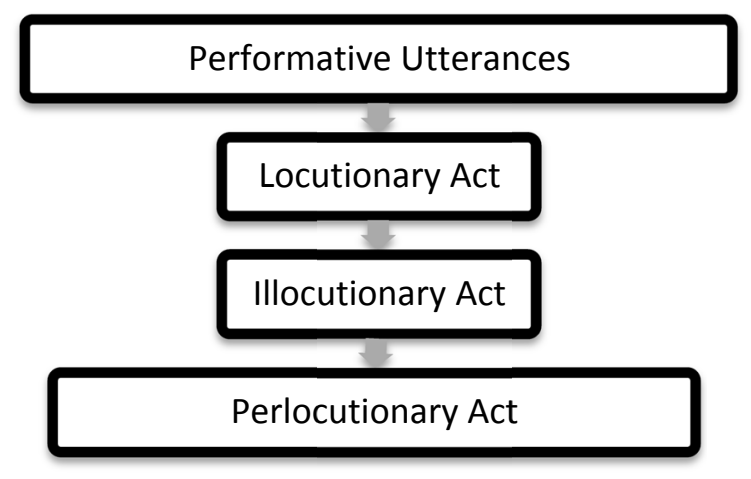

Figure 1. Speech Act Theory

A locutionary act refers to the conveyance of propositional meaning (Austin, 1962). In other words, the process of saying something that has a meaning. For example, when a reviewer writes a comment such as this: ' $I$ strongly suggest you to change 'use of power' to 'misuse' or 'abuse of power'.' it means the reviewer is giving a suggestion to the author. This locution is effective when the author comprehends its meaning. A locution must, then, comply with social norms and be bound to proper syntax, as shown by the illocutionary act.

An illocutionary act is defined as the performance of a particular utterance (Austin, 1962). The intention of saying something by means of some conventional force associated with it either explicitly or implicitly. By referring to the aforementioned example, the reviewer's comment is a demand made by the reviewer. The reviewer thinks that the phrase 'use of power' in the manuscript is not appropriate within the context, and thus a better and much more accurate language expression is needed. The demand constitutes a perlocution.

Therefore, a perlocutionary act is a deliberate act to produce the desired effect on the recipient's thoughts, feelings, or actions (Austin, 1962). In this case, even though the reviewer is suggesting, it is, in fact, a demand for the author to make the necessary changes. The author will most likely make the change as suggested by the reviewer.

Of the three linguistic acts in SAT, the illocutionary act has a purpose or attempts to get the receiver to take the necessary action. Searle (1976) classified the illocutionary act into five areas, namely, directives, expressives, representatives, performatives, and commissives (Table 1). This study applied Searle's illocutionary acts to examine the reviewers' comments in academic journal peer review reports. 
Table 1. Searle's illocutionary acts

\begin{tabular}{llll}
\hline & Illocutionary Acts & Definitions & Examples \\
\hline i. & Directive & To get people to do something & Suggest, clarify, instruct, demand, request \\
ii. & Expressive & To express the speaker's feelings & Praise, criticise, apologise, congratulate, compliment \\
iii. & Representative & To provide information & Claim, affirm, assert, inform, report \\
iv. & Performative & To bring immediate change to the world & Pronounce, declare, confirm, endorse, name \\
v. & Commissive & To commit the speaker to a future course of action & Promise, consent, refuse, assure, guarantee \\
\hline
\end{tabular}

\section{Methodology}

\subsection{Corpus Collection}

The corpus for this study consisted of 20 academic journal peer review reports obtained from an international peer-reviewed, indexed journal in Social Sciences, hosted by a university press in Malaysia. Permission was granted by the journal editor to utilise the reports for this study, and the reports were anonymised. The randomly selected peer review reports were meant for a journal issue in education studies. These reports consisted of reviewers' comments on the manuscripts sent by the reviewers to the journal editor.

\subsection{Corpus Management and Analysis}

The unit of analysis for this study was reviewers' comments in academic journal peer review reports. The reviewers' comments were available in electronic form. First, the researcher read and re-read the reviewers' comments to gain a general understanding of the reviews. Then, the researcher divided the reviewers' comments from paragraphs into sentences. Next, the researcher coded the sentences independently using the speech act analytical framework adapted from Searle (1976). The researcher identified the linguistic functions of the reviewers' comments.

To ensure the accuracy and reliability of the coding, two coders were given a set of reviewers' comments each, and they were required to code the reviewers' comments independently. Their coding was later compared with the researcher's coding to determine the inter-rater reliability (Cresswell, 2014) and managed to achieve a percentage agreement of $90 \%$. Table 2 shows an example of this categorisation.

Table 2. Reviewers' comments according to speech act categories

\begin{tabular}{lll}
\hline Speech Acts & Categories & Examples of Reviewers' Comments \\
\hline Directive & Suggestion & I strongly suggest you to change 'use of power' to 'misuse' or 'abuse of power'. \\
& Clarification & Whose experiences are being analysed? The teachers' or the students? \\
& Instruction & Reconsider the second last paragraph in the introduction (page 4). \\
Expressive & Praise & This was a very interesting article on a worthwhile topic. \\
& Criticism & The paper makes little contribution to the development of doctoral practice generally. \\
& Opinion & Personally, I think this may be overstated. \\
\hline
\end{tabular}

Qualitative content analysis was employed to analyse the reviewers' comments. It is a technique to systematically make inferences with objectivity and help identify the specific characteristics of such messages (Cresswell, 2013). In addition, Krippendorff (2004) claimed that content analysis is a "research technique for making replicable and valid inferences from texts (or other meaningful matter) to the contexts of their use" (p. 18). The selection of content analysis as the data analysis method in this study was based on two reasons. This method provides a researcher with the opportunity to discover and describe the focus of attention regardless of whether it is in an individual, group, institution, or social setting (Cresswell, 2013). Additionally, content analysis helps identify the trends and patterns in documents (Krippendorff, 2004).

\section{Results}

\subsection{Types of Speech Acts in Reviewers' Comments}

The first research question concerned the types of speech acts used during peer review by reviewers to provide written feedback to the authors. Based on the content analysis, the reviewers used two types of speech acts extensively. These speech acts are directive and expressive (Table 3). 
Table 3. Types of speech acts evident in reviewers' comments

\begin{tabular}{lll}
\hline Speech Acts & Frequency & Percentage (\%) \\
\hline Directive & 172 & 53 \\
Expressive & 154 & 47 \\
Total & 326 & 100 \\
\hline
\end{tabular}

A total of 326 instances of reviewers' comments were evident in the corpus. These comments were categorised into two main categories: directive and expressive speech acts. 53\% of the total comments were on the directive speech act. Essentially, the reviewers' comments were further categorised as suggestion, clarification, and instruction. The expressive speech act accounted for $47 \%$ of the total comments. Two categories were created, namely, positive and negative feedback.

\subsubsection{Directive Speech Act}

The analysis revealed that the reviewers used the directive speech act slightly more than the expressive speech act. A directive speech act is an act that commits the receiver of the message to do something (Searle, 1969). Since reviewers are assisting authors to revise the manuscripts, they have the responsibility to provide constructive feedback to the authors (Gosden, 2001; Hewings, 2004; Kourilová, 1996). By using the directive speech act, this can be accomplished.

Moreover, it was found that the reviewer comments were well-focused and specific. For instance, when the author received the directive comment: 'What is the significance of this model?', it is required that the author elaborate on the model or provide much more substantial evidence for supporting the use of the model in order to demonstrate its significance. The provision of feedback in such a manner can assist in the revision of the manuscript (Mungra \& Weber, 2010).

\subsubsection{Expressive Speech Act}

Another type of speech act which reviewers utilised was the expressive speech act. An expressive speech act is one in which the speaker expresses their feelings (Searle, 1969). As evidenced in the literature, it appears that reviewers express their views either in praise or criticism when reviewing manuscripts (Gosden, 2001). In this way, reviewers show that they understand the manuscripts and put forward their opinions on the manuscripts. For instance, a reviewer commented, 'This is a good piece of work'. It is likely that the author will feel appreciated when they receive such an expressive comment.

\subsection{Recurring Types of Speech Acts in Reviewers' Comments}

The second research question is to identify the most recurring types of speech acts used by reviewers when providing written comments on manuscripts. The two main speech acts, directive and expressive speech acts, were further divided into five categories. These categories are directive-suggestion, directive-clarification, directive-instruction, expressive-positive, and expressive-negative (Table 4).

Table 4. Types of reviewers' comments according to speech act categories

\begin{tabular}{lll}
\hline Types of Reviewers' Comments & Frequency & Percentage (\%) \\
\hline Directive & & \\
$\quad$ Suggestion & 78 & 24 \\
Clarification & 61 & 19 \\
$\quad$ Instruction & 33 & 10 \\
Expressive & & \\
$\quad$ Positive & 36 & 11 \\
$\quad$ Negative & 118 & 36 \\
Total & 326 & 100 \\
\hline
\end{tabular}

\subsubsection{Expressive-Negative Comments}

It is evident from the corpus that reviewers prefer to provide expressive-negative comments to authors (36\%). Most of the negative comments were focused on the content of the manuscripts. These comments included:

'Firstly, there seems to be a problematic link made between 'creativity' and 'originality', as if that was axiomatic, whereas it seems to me that this is precisely what might be problematised here'

'Unfortunately, the material presented in the paper does not provide a sufficiently robust or theoretically 
based study which can be readily adopted by other doctoral educators.'

\subsubsection{Directive-Suggestion Comments}

The second most recurring type of comments provided by the reviewers were directive-suggestions (24\%). For example:

'I think that it could be improved by a slimming down of the ambition behind it and a greater focus on one disciplinary orientation.'

'An expanded literature supporting your proposition and woven into your argument will also demonstrate how your contribution to knowledge relates to and builds on what is already known.'

\subsubsection{Directive-Clarification Comments}

The third most recurring type of comments provided by the reviewers were directive-clarification (19\%). For example:

'Whose experiences are being analysed? The teachers' the students?'

'In the abstract, findings are related to issues of concern. Are these issues unique to this setting or do these resonate with other PhD programs as discussed in the research literature?'

\subsubsection{Expressive-Positive Comments}

The fourth most recurring type of comments provided by the reviewers were expressive-positive feedback (11\%). These included:

'This is an interesting and useful contribution to the literature on doctoral education.'

'It was exciting to see that the author had approval of an Ethics Committee for this research.'

\subsubsection{Directive-Instruction Comments}

Directive-instruction was the fifth most recurring type of comments provided by the reviewers $(10 \%)$. For example:

'Rewrite to define bullying behaviour as "giving persistent insults or criticism, ignoring the victim, and expecting the victim to...etc."”

'Look for, and discuss, literature which talks about related experiences e.g., the literature on harassment.'

\section{Discussion}

By studying the speech acts used in academic journal peer review reports, this study aimed to better understand reviewers' comments. There were two main types of speech acts evident in the reviewers' comments. These are the directive and expressive speech acts. As opposed to the expressive speech act, the directive speech act was more frequently utilised. Considering the fact that the purpose of peer review is for reviewers to check the quality of research and to assist the authors in revising their manuscripts, it may be expected that reviewers prefer to use the directive speech act to provide suggestions. The directive-suggestion comments provided by reviewers should improve the manuscript's quality and ensure that the published manuscripts are accepted by the scholarly community (Bornmann \& Daniel, 2008).

It was also found that the reviewers provided directive-clarification comments. A possible explanation is that one of the objectives of peer review, which is undertaken for academic journals, is to ensure that ideas and arguments are clearly articulated and logical (Rigby et al., 2018). It is for this reason that reviewers provide comments on the methodology, findings, and the accompanying discussions in a manuscript, so that authors can present the most current research in their fields (Mungra \& Webber, 2010).

Nevertheless, the directive speech act was seldom used by the reviewers to provide instructions. It is possible that the reviewers are inclined to avoid face-threatening behaviour (Brown \& Levinson, 1987; Paltridge, 2017) for this reason. The term 'face-threatening behaviour' describes an act or behaviour that challenges someone's stand or choice. In this case, the reviewers may want to ensure the authors feel affirmed in social interactions (Mills, 2003).

It was also noted that the reviewers were polite by not commanding the authors to revise the manuscripts following the reviewers' comments. This resulted in reviewers not instructing the authors to make all the required changes. This finding supports an earlier study by Paltridge (2015), who investigated requests made by reviewers in academic journal peer review. The researcher found that reviewers mostly made indirect requests rather than direct ones. In the event that the authors take the suggestions given into consideration, the quality of 
their manuscripts will likely be enhanced, resulting in an increased chance of getting published.

Moreover, the study found a highly noticeable expressive-negative speech act in the reviewers' comments. Expressive-positive reviewers' comments, however, were few and far between. The fact that the reviewers provided negative comments may not come as a surprise as the findings aligned with previous studies on the negative review language (Hewings, 2004; Mur Dueñas, 2012; Wilcox, 2019). This phenomenon may be explained by the different reviewing styles of the reviewers. There is the possibility that varying opinions from the reviewers and different levels of research experience may provide much more negative feedback than positive.

Undoubtedly, the more negative comments or criticisms which are provided in academic journal peer review, the better the quality of the manuscript, resulting in an increased citation impact (Rigby, 2018). Yet, the negative comments could be overwhelming for the authors. Kwan (2013) claimed that novice manuscript authors were often "confused, discouraged or even shocked" (p. 213) when receiving negative reviews. They were not inclined to revise and resubmit their manuscripts thereafter.

The impact of the negative comments is psychological for the authors. The authors may feel depressed due to the overabundance of negative reviews (Gosden, 2003; Wilcox, 2019). As such, reviewers should refrain from using too much expressive-negative speech act in their comments and instead provide much more positive comments or a good mix of praise, criticism, and suggestions (Hyland \& Hyland, 2001).

Therefore, there is a need to foster a positive peer review culture and treat authors as valued members of the academic community. In reviewing manuscripts, reviewers should provide comments on how they would like to receive them, which are usually not harsh but "polite, honest, and clear to the authors" (Mavrogenis et al., 2020, p. 413). This can be achieved by increasing the use of expressive-positive speech act in academic journal peer review and balancing it with the directive-suggestions speech act.

\section{Conclusion}

\subsection{Research Contributions}

This study contributed to the literature on pragmatics and journal peer review by offering a speech act theory perspective on reviewers' comments in academic journal peer review reports. It is argued in the study that the journal peer review is a communication process, and a better understanding of the linguistic functions of reviewers' comments can help in understanding the reviewers' intentions in peer review, and thus encouraging effective revision. Therefore, this study echoes the findings of previous studies, such as Paltridge $(2015,2017)$, which showed that reviewers expected authors to address their comments, even when they were worded as suggestions, and not instructions.

Furthermore, the study contributed toward the intended practice. In view of the minimal use of the expressive-positive speech act in the reviewers' comments, reviewers are hereby urged to provide much more positive comments to encourage authors and be an advocate for a collegial peer review. When authors receive reviews which are harsh or overly critical, it can traumatise them (Hyland \& Jiang, 2020; Wilcox, 2019). Consequently, the authors may become frustrated and discouraged in their publishing endeavours.

\subsection{Research Limitations}

There are two limitations to this study which may limit its generalisation. Since the study only examined reviewers' comments from 20 peer review reports from one academic journal, the findings may not be generalised. While acknowledging the limited access to first-hand confidential data, future studies might attempt to gather and analyse a larger corpus of reviewers' comments from different academic journals. Data may be obtained through collaboration with journal editors and authors. Another limitation of the study may be the overlap of speech act categories. As language serves different linguistic functions, a reviewer's comment can simultaneously be a suggestion and an instruction. In this study, the researcher enlisted the help of two independent coders to ensure the accuracy of the results.

\subsection{Future Research}

Some promising research directions have been identified as a result of this study. Firstly, future studies may examine the reviewers' comments across disciplines and compare the similarities and differences in their speech acts. By understanding how reviewers from across different disciplines, including the sciences and social sciences, provide comments in academic journal peer review reports, this research will shed light on the pragmatics and journal peer review research. Additionally, since this study only focused on reviewers' comments, insights from authors can be obtained to understand the effects of the speech acts between the 
reviewers and the authors. It would be worthwhile to further investigate the authors' reactions and actions after receiving the reviewers' comments. Given the impact of the reviewers' comments on authors, a speech act taxonomy may be developed to help novice reviewers in providing effective comments on submitted manuscripts.

\section{References}

Austin, J. L. (1962). How to do things with words. Harvard University Press.

Bornmann, L., \& Daniel, H.-D. (2008). The effectiveness of the peer review process: Inter-referee agreement and predictive validity of manuscript refereeing at Angewandte Chemie. Angewandte Chemie International Edition, 47(38), 7173-7178. https://doi.org/10.1002/anie.200800513

Brown, P., \& Levinson, S. C. (1987). Politeness: Some universals in language usage. Cambridge University Press. https://doi.org/10.1017/CBO9780511813085

Coniam, D. (2012). Exploring reviewer reactions to manuscripts submitted to academic journals. System, 40(4), 544-553. https://doi.org/10.1016/j.system.2012.10.002

Creswell, J. W. (2013). Qualitative inquiry and research design: Choosing among five approaches (3rd ed.). SAGE Publications.

Creswell, J. W. (2014). Research design: Qualitative, quantitative, and mixed methods approaches (4th ed.). SAGE Publications.

Falkenberg, L. J., \& Soranno, P. A. (2018). Reviewing reviews: An evaluation of peer reviews of journal article submissions. Limnology and Oceanography. Bulletin, 27(1), 1-5. https://doi.org/10.1002/lob.10217

Fortanet, I. (2008). Evaluative language in peer review referee reports. Journal of English for Academic Purposes, 7(1), 27-37. https://doi.org/10.1016/j.jeap.2008.02.004

Gosden, H. (2001). "Thank you for your critical comments and helpful suggestions": Compliance and conflict in authors' replies to referees' comments in peer reviews of scientific research papers. Ibe'rica, 3, 3-17.

Gosden, H. (2003). Why not give us the full story? Functions of referees' comments in peer reviews of scientific research papers. Journal of English for Academic Purposes, 2(2), 87-101. https://doi.org/10.1016/S1475-1585(02)00037-1

Hames, I. (2007). Peer review and manuscript management of scientific journals: Guidelines for good practice. Wiley-Blackwell. https://doi.org/10.1002/9780470750803

Hewings, M. (2004). An 'important contribution' or 'tiresome reading'? A study of evaluation in peer reviews of journal article submissions. Journal of Applied Linguistics, 1(3), 247-274. https://doi.org/10.1558/japl.v1.i3.247

Hyland, F., \& Hyland, K. (2001). Sugaring the pill: Praise and criticism in written feedback. Journal of Second Language Writing, 10(3), 185-212. https://doi.org/10.1016/S1060-3743(01)00038-8

Hyland, K. (2015). Academic publishing: Issues and challenges in the construction of knowledge. Oxford University Press.

Hyland, K., \& Jiang, F. K. (2020). "This work is antithetical to the spirit of research": An anatomy of harsh peer reviews. Journal of English for Academic Purposes, 46, 100867. https://doi.org/10.1016/j.jeap.2020.100867

Kourilová, M. (1996). Interactive function of language in peer reviews of medical papers written by $\mathrm{NN}$ users of English. UNESCO-ALSED LSP Newsletter, 19(1), 4-21.

Kourilová, M. (1998). Communicative characteristics of reviews of scientific paper written by non-native users of English. Endocrine Regulations, 32, 107-114.

Krippendorff, K. (2004). Content Analysis: An introduction to its methodology (2nd ed.). SAGE Publications.

Kwan, B. S. C. (2013). Facilitating novice researchers in project publishing during the doctoral years and beyond: A Hong Kong-based study. Studies in Higher Education, 38(2), 207-225. https://doi.org/10.1080/03075079.2011.576755

Mavrogenis, A. F., Quaile, A., \& Scarlat, M. M. (2020). The good, the bad and the rude peer-review. International Orthopaedics, 44, 413-415. https://doi.org/10.1007/s00264-020-04504-1

Mey, J. (2001). Pragmatics: An introduction. Wiley-Blackwell.

Mills, S. (2003). Gender and politeness. Cambridge University Press. 
https://doi.org/10.1017/CBO9780511615238

Mulligan, A., Hall, L., \& Raphael, E. (2013). Peer review in a changing world: An international study measuring the attitudes of researchers. Journal of the American Society for Information Science and Technology, 64(1), 132-161. https://doi.org/10.1002/asi.22798

Mungra, P., \& Webber, P. (2010). Peer review process in medical research publications. Language and content comments. English for Specific Purposes, 29(1), 43-53. https://doi.org/10.1016/j.esp.2009.07.002

Mur Dueñas, P. (2012). Getting research published internationally in English: An ethnographic account of a team of Finance Spanish scholars' struggles. Iberica, 24, 139-156.

Paltridge, B. (2015). Referees' comments on submissions to peer-reviewed journals: When is a suggestion not a suggestion? Studies in Higher Education, 40(1), 106-122. https://doi.org/10.1080/03075079.2013.818641

Paltridge, B. (2017). The discourse of peer review: Reviewing submissions to academic journals. Palgrave Macmillan. https://doi.org/10.1057/978-1-137-48736-0

Rigby, J., Cox, D., \& Julian, K. (2018). Journal peer review: A bar or bridge? An analysis of a paper's revision history and turnaround time, and the effect on citation. Scientometrics, 114(3), 1087-1105. https://doi.org/10.1007/s11192-017-2630-5

Searle, J. R. (1969). Speech acts: An essay in the philosophy of language. Cambridge University Press. https://doi.org/10.1017/CBO9781139173438

Searle, J. R. (1976). The classification of illocutionary acts. Language and Society, 5(1), 1-24. https://doi.org/10.1017/S0047404500006837

Searle, J. R. (1979). Expression and meaning: Studies in the theory of speech acts. Cambridge University Press. https://doi.org/10.1017/CBO9780511609213

Shashok, K. (2008). Content and communication: How can peer review provide helpful feedback about the writing? BMC Medical Research Methods, 8(3), 1-9. https://doi.org/10.1186/1471-2288-8-3

Swales, J. (1996). Occluded genres in the academy. In E. Ventola \& A. Mauranen (Eds.), Academic writing: Intercultural and textual issues (pp. 45-58). John Benjamins. https://doi.org/10.1075/pbns.41

Tardy, C. (2019). We are all reviewer 2: A window into the secret world of peer review. In P. Habibe \& K. Hyland (Eds.), Novice writers and scholarly publication (pp. 271-290). Palgrave Macmillan. https://doi.org/10.1007/978-3-319-95333-5_15

Wilcox, C. (2019). Rude paper reviews are pervasive and sometimes harmful. Science, 366(6472), 1433. https://doi.org/10.1126/science.aba5502

\section{Copyrights}

Copyright for this article is retained by the author, with first publication rights granted to the journal.

This is an open-access article distributed under the terms and conditions of the Creative Commons Attribution license (http://creativecommons.org/licenses/by/4.0/). 